\section{artelogie}

\section{Artelogie}

Recherche sur les arts, le patrimoine et la littérature de l'Amérique latine

$14 \mid 2019$

Sensibilités : Arts, littératures et patrimoine en Amérique latine

\title{
Novas sensibilidades, performances e $o$ neoconcretismo : o exercício experimental de liberdade de Hélio Oiticica
}

\section{Robson Corrêa de Camargo}

\author{
CpenEdition \\ Journals \\ Edição electrónica \\ URL: http://journals.openedition.org/artelogie/3954 \\ DOI: 10.4000/artelogie.3954 \\ ISSN: 2115-6395 \\ Editora \\ Association ESCAL \\ Refêrencia eletrónica \\ Robson Corrêa de Camargo, « Novas sensibilidades, performances e o neoconcretismo : o exercício \\ experimental de liberdade de Hélio Oiticica », Artelogie [Online], 14 | 2019, posto online no dia 07 \\ janeiro 2019, consultado o 10 dezembro 2020. URL : http://journals.openedition.org/artelogie/3954 ; \\ DOI : https://doi.org/10.4000/artelogie.3954
}

Este documento foi criado de forma automática no dia 10 dezembro 2020

Association ESCAL 


\title{
Novas sensibilidades, performances e o neoconcretismo : o exercício experimental de liberdade de Hélio Oiticica
}

\author{
Robson Corrêa de Camargo
}

A line is a dot

that went

for a walk

Paul Klee

Uma linha é um ponto que foi contar um conto.

Paul Klee

1 (em tradução livre)

2 O objetivo deste trabalho é discutir alguns aspectos do percurso do trabalho do artista performer Hélio Oiticica (1937-1980), um artista brasileiro que se construiu como um artista/performer na crítica atuante sobre a arte de seu tempo e no observar das novas relações que sua obra estabelece no mundo. Hélio Oiticica organizou seu trabalho objetivando novas formas de produção de sensibilidade, redimensionando suas obras em diferentes ocupações de espaço e na sua interação/inter-relação com o público ativo e partícipe da obra, procurando não mais um observador, mas um público atuante, um participador, um participator, que estabelece outra lógica ao inserir o espectador artista no presente da execução da obra.

3 Sua arte, assim como a de seus contemporâneos e companheiras Lygia Clark (1920-1988) e Lygia Pape (1927-2004), não visava apenas romper com o suporte fixo, mas produzir uma obra de arte que invadiria o locus público e com ele interagiria, numa relação dinâmica e presente entre ser e obra. Oiticica afirmava, em 1971, em plena Nova Iorque, que a performance não devia ser preform, preformada (OITICICA, 1971 : PHO 0511/71). Em sua compreensão a performance deve existir como ação 
simultânea, arte em ato, não o de ser pré-elaborada para uma apresentação. 0 público não pode ser complementar na relação com o objeto artístico (OITICICA, 1971 : PHO 0511/71). A obra de arte como ação no ambiente, arte como sinal, arte ambiental, onde um som e um grito podem ser objeto.

"Exercício experimental de liberdade", como ele mesmo chamava suas intervenções, nome sugerido pelo crítico Mario Pedrosa (1900-1981), foi o leit motiv de sua obra múltipla, e teve como impulso o ampliar ou o expandir das relações de sensibilidades até então estabelecidas (PEDROSA, 1973 : 84-143).

A superação da arte contemplativa dominante até aquele momento, para uma arte que procurava afetar e propor novos comportamentos e que se libertava dos ditames do autor, é uma das grandes conquistas do movimento a que ele se filiou, e que teve importantes precursores em nosso país. A arte de Hélio Oiticica procurou uma nova dimensão ética, social e política, mesmo no marco dos tempos iniciais da ditadura militar que nos comprimia. Ou ainda, como definiria o crítico Mario Pedrosa (1900-1981), a arte de Oiticica convocava o envolvimento do espectador em trabalhos que "não mais se concentravam na materialidade da forma e na objetividade da linguagem", mas num ato de arte e vida e na procura da arte total (PEDROSA, 1973 : 143).

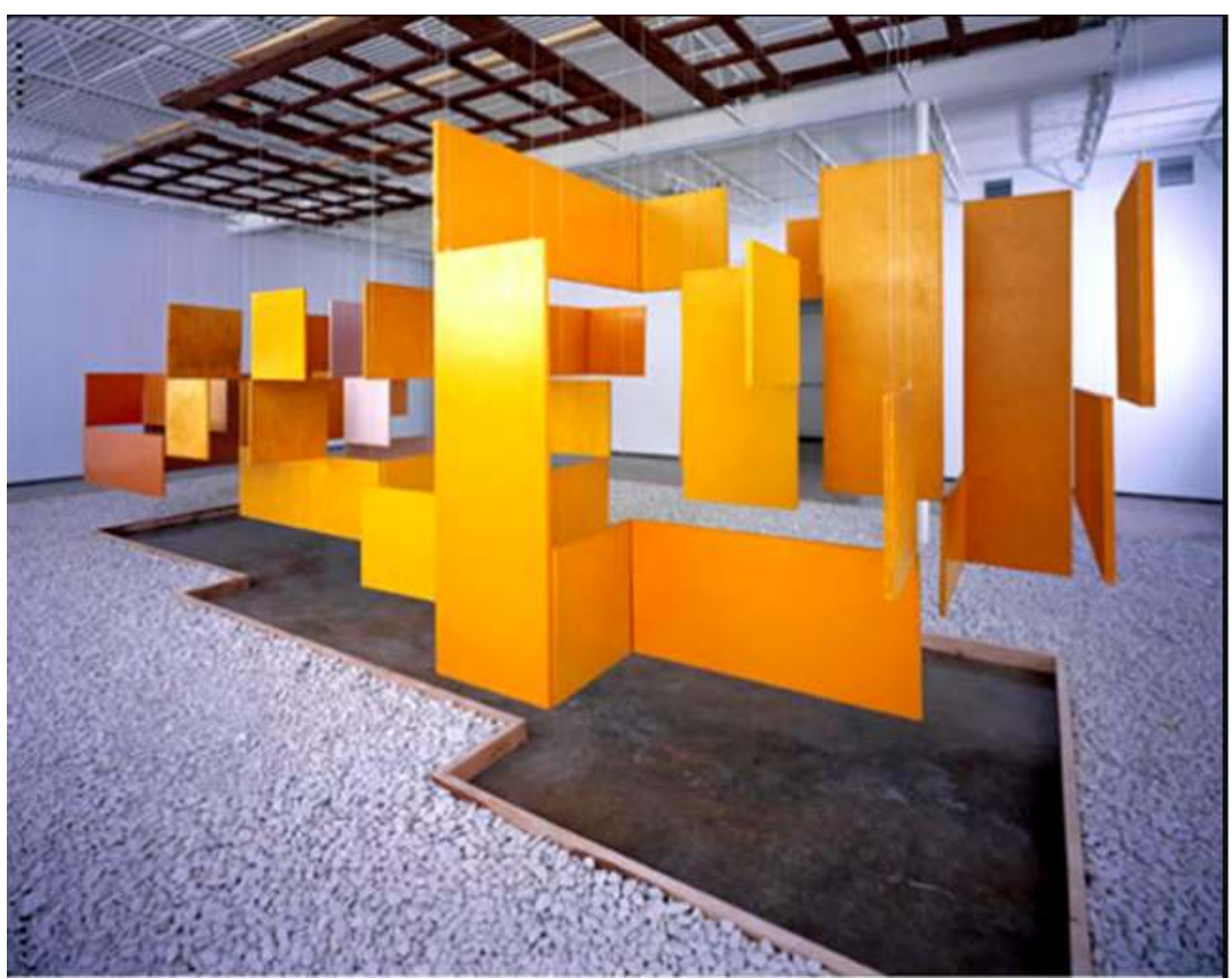

Grande Núcleo (Grand Nucleus) de Hélio Oiticica, 1960-1966. Óleo e resina em madeira, dimensão geral $6.7 \mathrm{~m}$. x 9,75 m. imagem em

http://www.antoniomiranda.com.br/poesia_visual/img/movimento_neoconcreto_helio_oiticica.jpg acesso em 15 outubro 2018.

Oiticica procurava o campo ampliado da pintura, a superação do quadro, e uma arte ambiental, que incorporasse e se tornasse o ambiente circundante, suas contradições e contra discursos. Esta perspectiva de trabalho tem seus inícios nos Núcleos, denominação de placas de madeira geométricas diversas, em diversos tamanhos, suspensas e expostas juntas, em três/partes cores que arrebentavam a estrutura 
bidimensional e se arremessavam ao espaço. Um quadro abstrato que se transmutava no espaço, inseria o público na obra ou arremetia o quadro na vida do espectador. Para que se possa absorver o desdobramento expandido da cor no Núcleos de Oiticica é preciso que o participante adentre nesta estrutura de placas coloridas, cercando-se delas e vendo-as por todos e múltiplos ângulos, dentro/fora. $\mathrm{O}$ espectador incorpora o ponto de vista do artista e perambula pela obra, desconstruindo ou construindo múltiplas perspectivas.

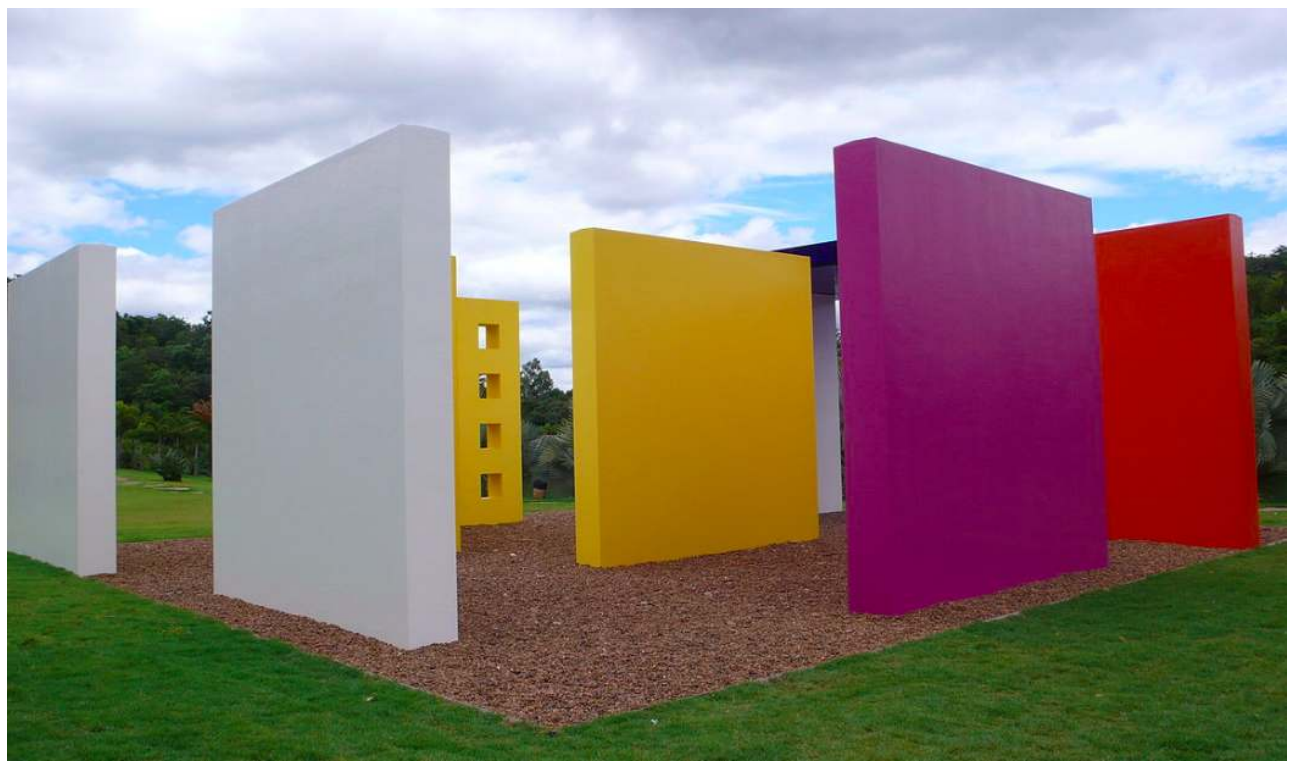

Núcleo de Hélio Oiticica, 1960. Instituto Cultural Inhotim em Brumadinho/Minas Gerais/Brasil. https:// commons.wikimedia.org/wiki/File:Inhotim_Oiticica_04.jpg acesso em 20 dezembro de 2018

7 Sua fase seguinte, não mais formas coloridas que saltavam aos espaços, agora são Bólides (Fireballs), desenvolvidos entre 1963-1967, 64 trabalhos que permitem a luz penetrar no seu interior, produzindo assim recipientes de luz. Procuraram decompor ou desestruturar a matéria prima constitutiva da arte, pó de cores encapsuladas que se reuniam em formas geométricas várias, em relações múltiplas com embalagens de vidro, plástico, cimento que compunham formas distintas em distintas relações. 0 espectador é intimado a se envolver, pisar, entrar em contato com o material. Arte como experiência no movimento. Bólide é como se chama a um grande meteorito que, inflamado, brilhante, atravessa a atmosfera, deixando um rastro luminoso ou explodindo. Assim se nomina qualquer corpo que se desloca em grandes velocidades, assim explode a arte de Oiticica.

O novo concreto, o neoconcreto, procurava uma produção engajada, que dialogasse com o ambiente que o cercava, trazendo a realidade e o público para dentro da obra, com materiais "puros" que podem ser manipulados pelo observador, como pigmento, terra, zarcão. Assim são os Bólides. Num movimento de tele transporte a matéria se condensa, se adensa, se projeta, se destrói. Estabelecem-se assim as bólides, multiplicam-se e aprofundam a relação intuitiva do publico com a obra, arte expandida que deforma o espaço ao redor, suga o público para as formas primeiras da arte, perturbando o movimento ao redor e convidando o observador ao processo de atuação. 


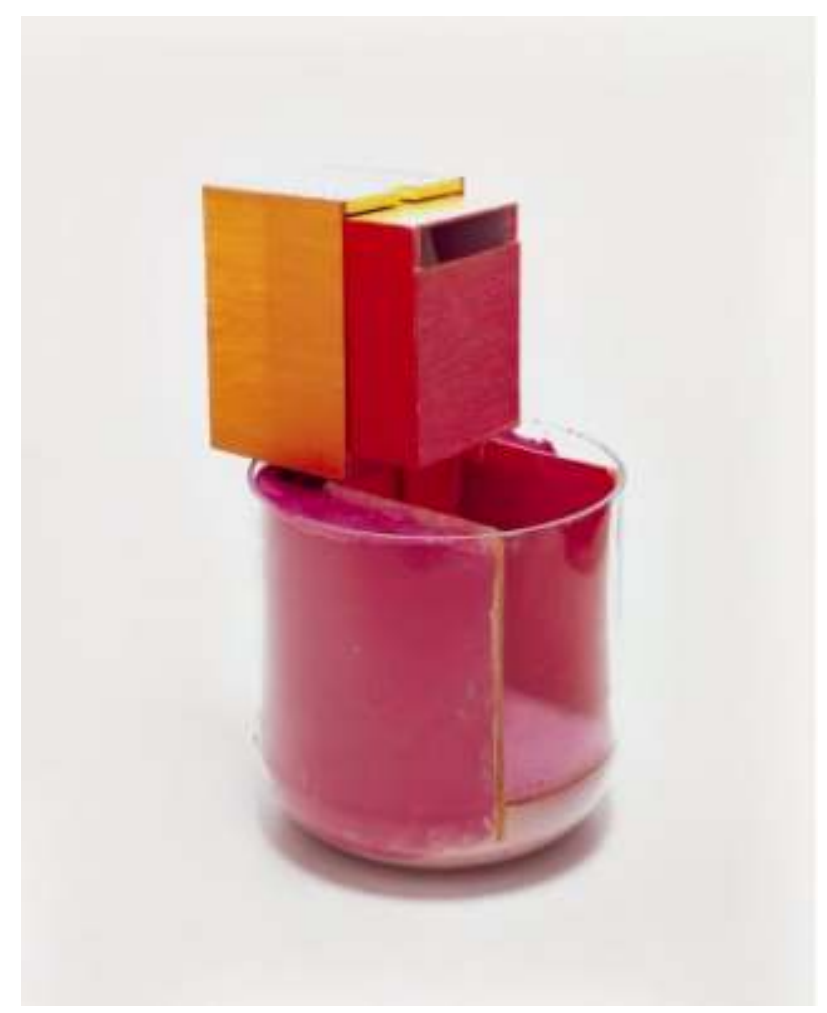

B08 Bólide de vidro 02 (1963-1964) vidro: 270- mm x 280 mm diâmetro. Caixas de madeira 205 mm x 144 mm x 140 mm. Coleção de Luiz Antonio Braga, Rio de Janeiro. Imagem da Galeria Tate

https://www.tate.org.uk/whats-on/tate-modern/exhibition/helio-oiticica-body-colour/helio-oiticica-exhibitionguide/helio-5 acesso em janeiro de 2019.

Estes foram alguns dos passos prévios que desaguariam nos Parangolés, a experiência tátil de cores em movimento envolvente de um espectador in motu proprio. Se antes o espectador era convidado polidamente a entrar na obra, agora ele deve tomar para si o objeto e os meios de sua produção, participator de uma obra dançada, que só será obra se possuída. Uma obra que procura incorporar, desenvolver-se na relação completa e complexa do homem com a Natureza, tal como dissecado por Marx em seus escritos Econômico e Filosóficos (1844). Um ser humano "sensível" que se apropriava da obra, ser em obra, homem natureza sensível.

10 A Declaração Princípios Básicos da Nova Vanguarda, de 1967, manifesto assinado por vários artistas, entre eles o artista multimídia Antônio Dias (1944-2018), a "não artista" Lygia Clark, como ela se auto proclamava, e a performer multimídia Lygia Pape, além do próprio Hélio Oiticica. Propunha-se nele novos parâmetros para o que ainda se chamava de uma arte "de vanguarda" e propugnava-se nesta Declaração uma arte que pudesse contribuir para que se alterassem as "condições de passividade ou estagnação" do público e para que a relação obra-público fosse estendida, sua manifestação deveria então se dirigir a "todos os campos da sensibilidade e da consciência do homem". Conforme o Catálogo da exposição Nova Objetividade Brasileira ocorrida no MAM-RJ em 1967 (https://vdocuments.site/declaracao-dos-principios-basicos-davanguarda-1967.html).

11 Á luta por uma nova relação sensível com o público, apontava aquele manifesto, enquanto se gestava o que seria o ato institucional número cinco de 13 de dezembro de 1968, que determinaria o fim da pouca liberdade ainda existente naqueles tempos de ditadura, impondo-se por algum tempo o silêncio. Manifesto aquele que defendia ser 
necessário não apenas perceber a obra, mas o se introduzir nela, envolver o público no entendimento crítico da realidade do artista e do ambiente, onde a execução da obra deveria se fundamentar na liberdade cerceada. Ao mesmo tempo esta arte ambiental deveria procurar uma linguagem que buscasse superar as condições paralisantes desse ato de liberdade promovido, arte que buscava, portanto, não o entorpecer.

Este paradoxo da liberdade, arte como experiência, presente na apresentação/recepção da obra de arte, mostra uma das questões centrais que foi invadindo o trabalho de Oiticica e de outros artistas brasileiros na década de 1960, e que seria o terreno fértil daquilo que foi chamado Tropicalismo, no teatro, na música, na dança, na vida.

13 A linguagem da arte necessitaria assim estar em consonância com o desenvolvimento dos acontecimentos de seu entorno e procurar dinamizar os fatores de apropriação da obra, introduzindo o público nela ou se introduzindo no público, assim o projeto caminhava no sentido de imergir o artista na "atividade criadora na coletividade" e vice-versa.

14 A múltipla proposição dos signatários daquela exposição, visava a "invenção de novos meios capazes de reduzir à máxima objetividade tudo quanto deveria ser alterado, do subjetivo ao coletivo", "da visão pragmática à consciência dialética (item 6)". Apresentando, acrescentando ou inserindo um sentido cultural no trabalho criador, o movimento adotaria não apenas a obra e sua exposição poli sensível, mas ainda todos os métodos possíveis de comunicação com o público, "do jornal ao debate, da rua ao parque, do salão à fabrica, do panfleto ao cinema, do (rádio) transistor à televisão". Não! Isto não era novo, mas não era a novidade que procuravam.

Esta não era uma nova proposição individual do artista Oiticica, alguns artistas brasileiros procuraram também jogar para fora seus demônios, ou incorporá-los, na relação obra-público. Um deles foi a própria Lygia Clark, que, já em 1957, dez anos antes, em seus cadernos de notas e pensamentos apontava: "A obra (de arte) deve exigir uma participação imediata do espectador e ele, espectador, deve ser jogado dentro dela". (PEDROSA, 1980 : 14-17). Aponta Pedrosa que, com o trabalho de Lygia Clark, o conceito de espaço, como o de realidade, sofrera profunda alteração, pois não haveria mais um espaço contemplativo, mas "um espaço circundante" (PEDROSA, 1980 : 14-17). A arte de Hélio Oiticica, assim como o LP Tropicália ou Panis et Circenses, a encenação de Rei da Vela, a arte antiarte do final dos anos 1960, estabelecem novos parâmetros de conhecimento e integração da vida e da arte, com a paródia, a ironia, o deboche, a reconstrução do passado, nos marcos vividos da ditadura militar brasileira. A antropofagia revolucionária assim se instalava num reverter das expectativas e das vivências estabelecidas até então pela arte no Brasil. 


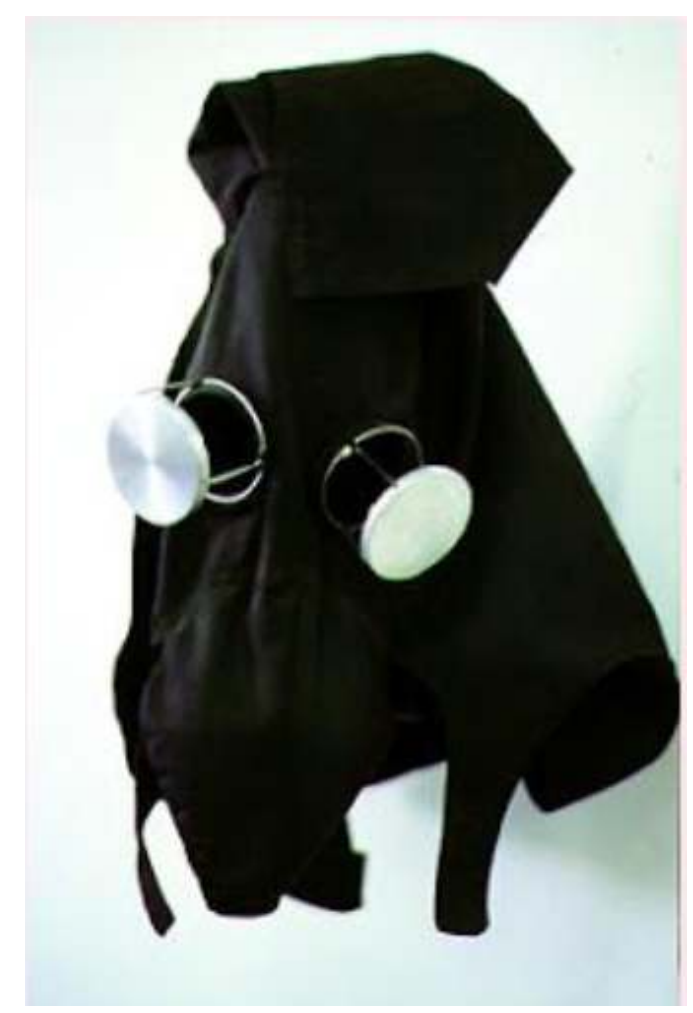

Máscaras Sensoriais de Lygia Clark. 1967. http://contemporaneaarte.blogspot.com/2009/10/asmascaras-sensoriais-lygia-clark.htm/ acesso em 18 de outubro de 2018.

Lygia Clark nas suas Máscaras Sensoriais, de 1967, procurava disponibilizar o tocar, o cheirar, o apertar, o sentir, o interagir. Neste o publico artista deixaria um pouco de si e levaria um pouco do que a artista desejava. Assim também seus Bichos - esculturas de chapas de metal para serem manipuladas, que poderiam se transmutar em diversas formas a partir do desejo do usuário; nos entrelaces de corpos na fase denominada Nostalgia do Corpo ou ainda nas Máscaras Sensoriais que provocavam uma explosão de sentidos ao participante. Os homens e a mulheres deveriam encontrar o fantástico dentro de si, pelo tato, sons e odores, o participante poderia então ser levado "a um estado equivalente ao da droga", pretendia-se nelas o perder do contato com a realidade externa e a imersão no simbólico interior projetado.

As máscaras tinham saquinhos de sementes e ervas na altura do nariz, cada uma com um cheiro característico, perto do ouvido materiais que produziam ou provocavam sons, nos olhos reduzidos orifícios com diferentes materiais, o objetivo era isolar o indivíduo, cortar as conexões com o externo e convidar a uma viagem com seu próprio corpo, interior e pessoal.

Outra artista destes precursores, Lygia Pape, em 1968, seguindo as trilhas de Oiticica, construiria a performance Divisor, um pano branco de cerca de 30 metros com muitos buracos, para que as pessoas o vestissem, coletivamente, e andassem em grupo pelas ruas do mundo. A ação fora realizada pela primeira vez em 1967 com um grupo de crianças da Favela da Cabeça, no Rio de Janeiro. Na performance, cerca de 100 pessoas preenchem um pano de 30 por 30 metros. Realizada durante a ditadura militar, a performance era uma crítica à repressão do regime, especialmente à vigilância do espaço público, quando não se permitia andar em um grupo de mais de três pessoas. 


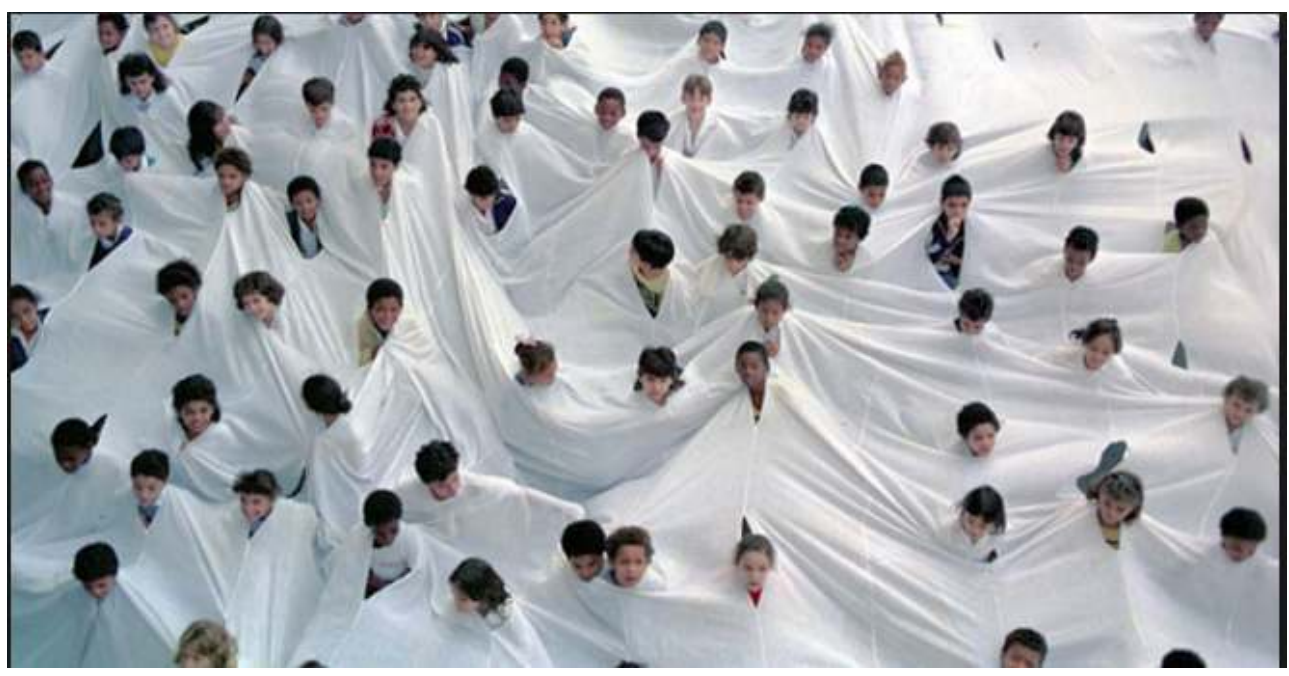

Divisor. Lygia Pape, 1968.

http://www.arte.seed.pr.gov.br/modules/noticias/article.php?storyid=741 Acesso em 15 de outubro de 2018.

Este movimento em busca do não contemplativo ou da criação coletiva, público inserido, amálgama arte e vida, arte em processo, procurava uma arte colaborativa, acompanhava as novas possibilidades potencializadas pela revolução industrial, inserindo novos paradigmas que incorporavam a cultura de massas. Alargavam-se os critérios para se atingir o ser humano, despertando-o para a participação renovadora e para a análise crítica da realidade. Assim esta arte estaria imersa na diversidade das experiências que se presentavam e procurava construir uma integração na comunidade das experiências. Experiências que procurariam, ao mesmo tempo que apresentavam uma vivencia de liberdade, e que objetivava uma nova objetividade, para "superar as condições paralisantes dessa liberdade". o barato da obra de arte não deveria torpor a realidade.

Na exposição do MAM/RJ, de abril de 1967, esta mostra coletiva da Nova Objetividade Brasileira, concentrou ainda o trabalho de outros grandes artistas como o cenógrafo Flávio Império (1935-1985), Glauco Rodrigues (1929-2004), Carlos Vergara (1941), Sérgio Ferro (1938), o crítico Mario Pedrosa (1900-1981), reunindo diferentes vertentes das vanguardas nacionais, arte concreta, neoconcreta.

21 Novas figurações em torno da "nova objetividade", um termo que, para Oiticica, traduziria fielmente as experiências e trajetórias das vanguardas brasileiras, numa tendência de superação dos suportes tradicionais (pintura, escultura) em proveito de estruturas ambientais e objetos. Numa perspectiva que hoje poderia ser chamada precisamente de neocolonial, procurava-se a criação e defesa das produções locais, e que estas não fossem apenas simples cópias do que se produzia nos grandes centros internacionais. Gestava-se aí a antropofagia, onde se digeriam os pensamentos emanados da Europa e América do Norte e se provocavam novos olhares e tocares.

Oiticica e os artistas brasileiros reunidos procuraram um campo ampliado de suas produções artísticas. Este núcleo de artistas, com intensa experiência internacional, pode olhar com desdém ao surgimento da performance art em Nova Yorque. Oiticica afirmará que as experiências que presenciou a partir de 1970 naquele país, contrariamente ao que propagavam e propagam até hoje, como ato revolucionário, se tornavam, para ele, apenas um "lugar comum". A imensa maioria da performance art 
seria para ele apenas uma arte tradicional que não tocava "as questões centrais do fenômeno artístico em seu tempo". Chutava Oiticica o pau da barraca da arte de nossa matriz.

Para Oiticica a vanguarda norte-americana se rendia docilmente ao mundo do espetáculo norte-americano, pois conservava a antiga relação da performance, da arte para se ver. Observava ele que à parte as raras experiências-limítes do underground, as performances de Yoko Ono e o rock-implosão de Hendrix-Stones - o mundo do espetáculo norte-americano, e mesmo das artes, permanecia repetindo o antigo estereótipo da performance para ver, não colocava a participação do espectador em questão. Vai exemplificar concretamente essa situação ao comentar uma apresentação do artista Willoughby Sharp, que deixava a plateia sentada a uma distancia segura "como nos velhos musicais". Decretava Oiticica: "é muito chato e eu não posso suportar esta merda passiva: ressoa como uma missa, e a maioria das performances aqui são assim (it's boring and I can't stand all this passive shit: sounds like church performance, and most performances here are like that). (OITICICA, arquivo 1150.71, 1970?).

Oiticica identifica que a nova vanguarda norteamericana apenas maquiava o velho conceito de arte do século XIX. Assim comentava Hélio Oiticica, direto de Nova York (vale a pena o longo comentário):

No Brasil, dos anos 50, surgiram problemas que até hoje são novidades aqui, ou melhor, nem sequer foram abordados; quando se pensa em, p.ex., performances, se pensa sempre (aqui) num nível de espetáculo, que nada transforma a ideia que se tem de "espetáculo" (estou com um livro genial do Guy Debord, Society of the Spectacle [original de novembro de 1967 La Société du Spectacle, em inglês a edição é de 1970)], que coloca tudo isso up to date; uma maravilha, e do qual quero tirar material para esse argumento); há uma ânsia aqui de inventar coisas, mas que acabam por se resumirem em invenções de detalhe (como nos objetos de consumo), pra dizer: "eis o novo"; num nível de criação, o "novo" nunca é absoluto: no "novo" o "velho" toma uma parte importante, porque se transforma de verdade; ao passo que a absolutização do conceito de "novo" passa a ser uma máscara por trás da qual se esconde o "velho" (não sei se alguém já disse isso;...) portanto quando há um nível de transformação , é de se esperar que seja uma transformação autêntica; essas transformações, como você sabe, podem durar uma obra-vida inteira (penso que quando morrer, tudo o que quero ainda estará para ser abordado em grande escala); é preciso e essencial portanto que o artista se repita no que diz: a insistência a determinados argumentos é importante; não me importo em ter que durante toda a vida ter que falar na conceituação de "arte", "obra de arte", "coisa", "objeto", "espectador e espetáculo", "participador", etc.; (Arquivo Hélio Oiticica 1150.71) 


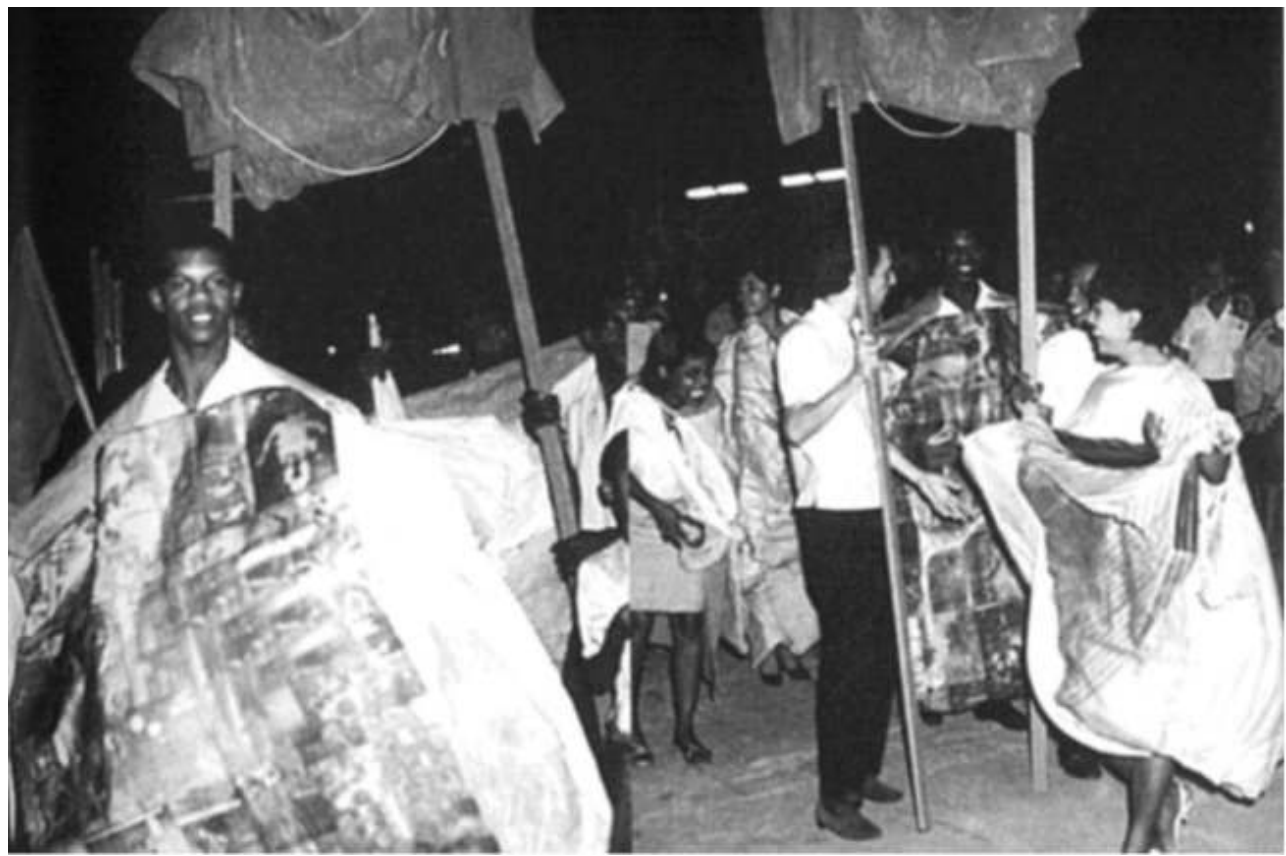

Hélio Oiticica na manifestação do MAM-RJ 1965. Imagem em https://periodicos.ufpa.br/index.php/ ppgartes/article/viewFile/4863/4360. Acesso em dezembro 2018 do IV Centenário da cidade do Rio de Janeiro, no Museu de Arte Moderna (MAM/RJ). Foi realizada entre os dias 12 de agosto e 12 de setembro. Reunira vinte e nove jovens artistas, treze europeus e dezesseis brasileiros. Apontava esta uma relação existente entre a nova figuração francesa e a brasileira. Opinião 65 inspirava-se no entusiasmo geral que o show organizado pelo Teatro de Arena no Rio de Janeiro despertara, foi a primeira manifestação cultural organizada após e contra o golpe militar de 1964 . O show do Teatro Opinião fora estrelado por Nara Leão, depois substituída pela nova cantora Maria Bethânia, João do Vale e Zé Ketti, com direção de Augusto Boal.

(opinião 65" ficaria marcada pela apresentação dos Parangolés de Hélio Oiticica, fora do museu, quando junto com os "crioulos" passistas da mangueira paramentados de parangolés, capas e estandartes em movimento, serão expulsos do recinto sendo obrigado a dar continuidade a sua performance nos jardins do MAM, numa época que os brancos finos visitavam os museus de terno e gravata.

27 A dança parangolé de Oiticica procurava incorporar corpo e obra, ato improvisado, gesto ritmo, onde o corpo se conforma em contínua transformabilidade, os objetos como imanência expressiva. Oiticica procurava um ato corporal expressivo que se transformasse sem cessar (OITICICA, $1965: 1-4)$ ). Como bem expressara:

A experiência da dança (o samba) deu-me portanto a exata ideia do que seja a criação pelo ato corporal, a contínua transformabilidade. De outro lado, porém, revelou-me o que chamo de 'estar' das coisas, ou seja, a expressão estática dos objetos, sua imanência expressiva, que é aqui o gesto da imanência do ato corporal expressivo, que se transforma sem cessar. (Oiticica, 1986: 75)

Os Parangolés só existem em movimento, um manifesto da cor no espaço ambiental através do seu arejamento contínuo. Parangolé. O espectator veste a capa que se constitui como camadas de pano de cores que se revelam à medida que se movimentam 
dançando, correndo, pulando, a obra exige que o espectador se movimente, que a dance. $O$ vestir do parangolé já é um transvestir, como afirmava Oiticica:

“[...] As imagens liberadas na dança são móveis, rápidas, inapreensíveis - são o oposto do î́cone, estático e característico das artes ditas plásticas - em verdade a dança, o ritmo, são o próprio ato plástico na sua crudeza essencial - está aí apontada a direção da descoberta da imanência. Esse ato, a imersão no ritmo, é um puro ato criador, uma arte - é a criação do próprio ato, da continuidade; é também, como o são todos os atos da expressão criadora, um criador de imagens - aliás, para mim, foi como que uma nova descoberta da imagem, uma recriação da imagem, abarcando, como não poderia de ser, a expressão plástica na minha obra". (OITICICA apud FAVARETTO, $1992: 115$ ).

O Parangolé são três, tenda, estandarte e capa. Na tenda o participador penetra para desvendar a estrutura-cor espacial da obra, o estandarte é a estrutura ligada ao ato de carregar do participador, a capa é a experiência propriamente dita, podendo assistir a outrem, um vestir, dançar em obra coletivo, formando um espaço inter-corporal. Assim nos Parangolés o participador ou participator tem a experiência da cor em seu próprio corpo, experiência orgânica, entre os elementos.

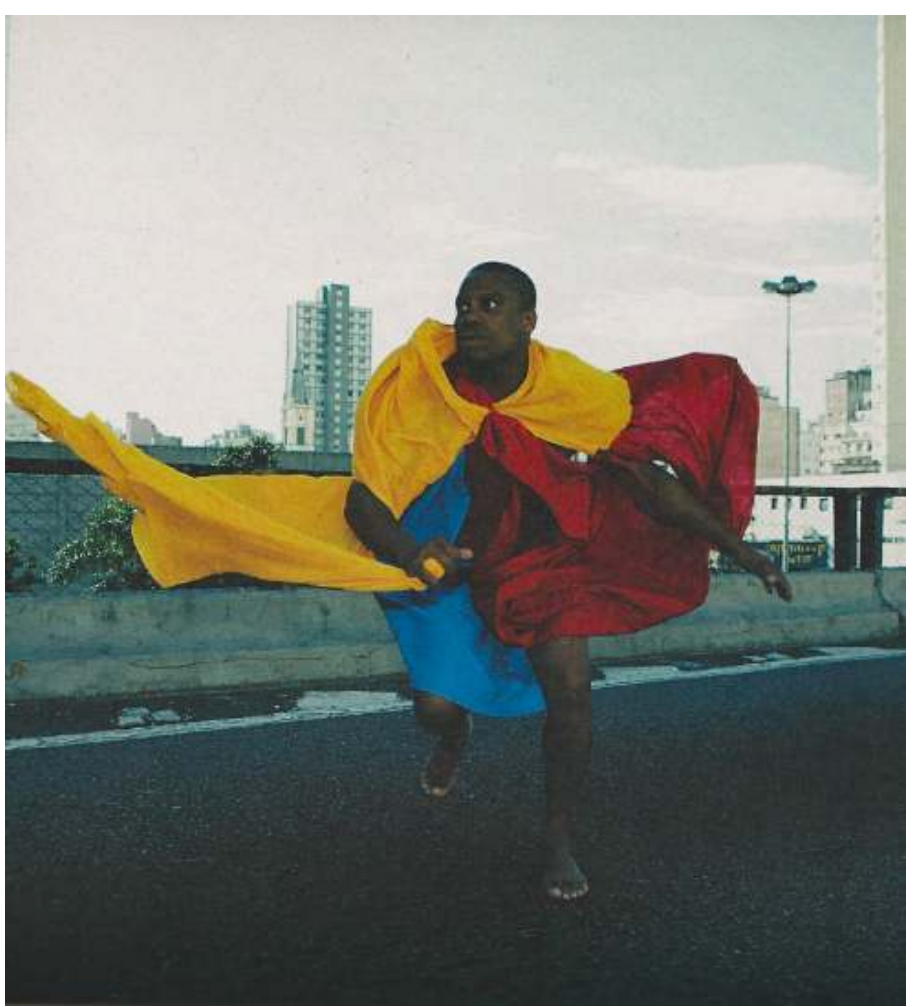

Dançando o Parangolé. https://br.pinterest.com/pin/51932201932720096/ acesso em 20 de outubro de 2018.

Se a discussão colocada pelos artistas neoconcretos na década de 1960 no Brasil foi fundamental, na relação dinâmica com o ambiente, estabelecendo novas relações com as pessoas que envolvia, outras questões merecem ser acrescentadas na relação com o sensível e que podem aprofundar ou amplificar o entendimento da questão da relação com a obra de arte e do envolvimento do artista com o público. A arte é uma manifestação única de linguagem, talvez uma não linguagem, uma experiência mítica, ou icônica. 


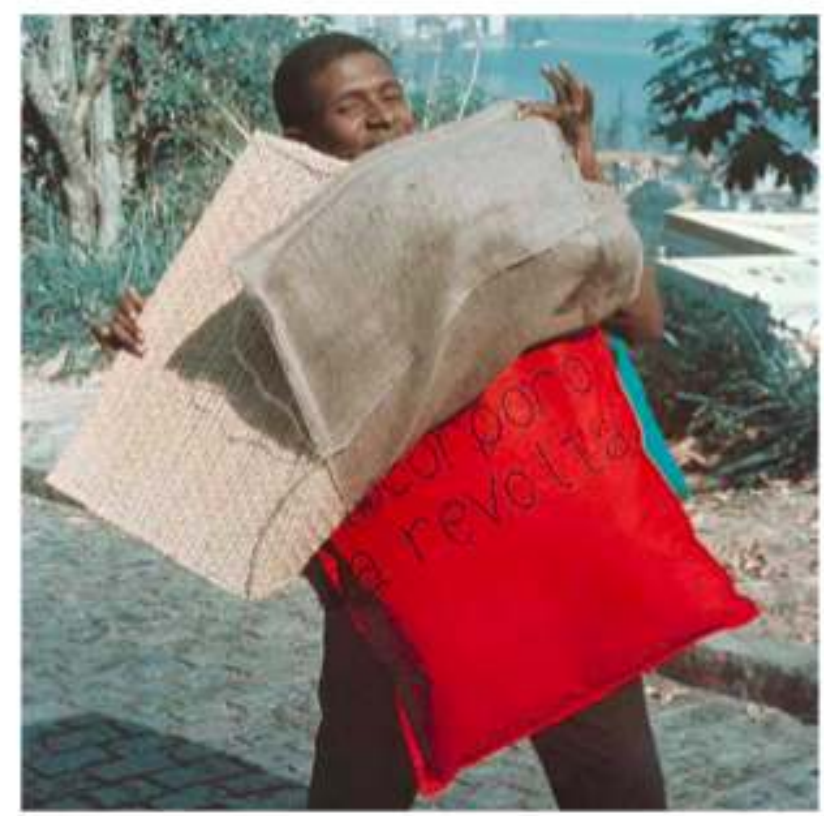

Parangolé "incorpora a revolta" https://br.pinterest.com/pin/61502351141470049/ Acesso em15 de outubro de 2018.

\section{Susanne Langer, a arte como experiência última do sensível}

Susanne Langer (1895-1985), ao procurar entender o processo simbólico, humano em seu livro Sentimento e Forma de 1953 (1980, ed. Perspectiva), descreve que, tanto a arte como a linguagem têm em comum o estruturar nas articulações dos símbolos. Entretanto, Langer aponta distinções em suas naturezas, processos ou movimentos, seja na linguagem como na arte. Para ela os símbolos se compõem de forma distinta em ambos, o que levaria a que não apenas percebêssemos a diferença entre ambos, mas distanciássemos nosso entendimento de arte como linguagem, por serem de naturezas diversas.

32 A linguagem, gestual, falada ou escrita, é discurso composto a partir de símbolos elementares - sentenças, orações, frases, palavras, e mesmo com partes significativas de palavras: raízes, prefixos, sufixos, etc.; símbolos selecionados, arranjados e permutáveis de acordo com "leis da linguagem", leis publicamente conhecidas por todos que tendem a comunicação. A linguagem é assim um sistema de símbolos que necessariamente se estrutura nesta relação para o entendimento da comunicação.

A arte, ao contrário, se organiza como símbolo único, sem uma referência necessária na natureza ou na sociedade e sem a necessária decomposição em seus elementos simples, num terreno que se constrói sem a obrigatoriedade das leis do significado, composto por partes aleatórias que podem se contradizer. A arte tem como objetivo não o esclarecimento de uma ideia, o de "transmitir" algo, mas o possibilitar uma experiência verdadeira, mas não o de ser uma repetição de determinada outra experiência ou mesmo de uma forma de imitá-la. 
Seus elementos isolados, suas partes, ao acaso, jogam um papel em sua forma total, são determinados por ela, mas não falam de si. (LANGER, $1980\{1953\}$ : 383). O produto da arte então é símbolo primeiro, não um simbolismo de outro algo. Se a linguagem é um meio, para Langer, a arte é um dado. Se a linguagem é meio, media, a arte é um fim, e um começo.

Para Langer uma obra de arte é sempre um símbolo primário, único, indivisível, não discursivo, um símbolo que chama presentacional, não é meio, não re-presenta, pois presente, se presenta, e este pode ser analisado, mas não reduzido à análise. É um símbolo presentacional construído em um "processo de síntese de elementos", sobrepostos, justapostos, contrapostos, apostos. Seus elementos se compõem de forma totalizante (LANGER, 1980 : 383). A arte assim não é redutível a nenhum de seus elementos, ao estado subjetivo de seu autor na época de sua produção, a uma biografia ou meio cultural, nem a uma determinada afirmação: “Ceci n'est pas une pipe" (MAGRITTE, 1928/9).

6 Arte é um símbolo primeiro, primevo, primordial, não um simbolismo de algo, seus elementos, ou suas partes jogam um papel na totalidade, pela totalidade. $O$ objeto arte é uma forma total ou completa. Mônada, monas, um todo que não tem partes. Não é expressão do eu, embora possa se constituir do eu e do não eu, de significados, de biografias, de mensagens.

ainda outra questão fundamental. Se o objeto artístico deve ser afastado de seu entendimento lógico descritivo, de sua compreensão analítica como instrumento de linguagem, que não o enquadra, para Susanne Langer este objeto artístico único é ainda um símbolo manifesto do sensível humano, um sensível concretizado no produto da arte. Mito que carrega narrativas, sensível objetivado.

O produto da arte é uma forma de sensível. Assim a Arte não seria uma forma de expressar outros, emoções e/ou ideias, como se costuma afirmar. Como se vê a compreensão da arte como linguagem limita a arte ao procurar-se entende-la como um meio de expressão de outra coisa, de algo, como meio e não como coisa em si.

Mas atenção há que se entender este sentimento (feeling), para que não se perca o sentido. Sentimento pode ser o tato, a sensação, o sentimento, a emoção, a opinião, o pressentimento, a impressão, a suspeita, a sensibilidade, a ternura, o afeto, o gosto. 0 sensível, ou um sensível. Assim temos um feeling que não deve ter necessariamente sentido (entendimento, razão), nem ser o reconhecimento de sensações, pois está se falando de um sensível, sujeito.

0 O sensível que estrutura a obra de arte tem que ser entendido de forma abrangente, pois este pode ser, não apenas o sentimento, a emoção ou a sensação, mas também a imaginação, a memória e o raciocínio dentro do processo. A experiência de sensível (felt experience), experiência sentida, é elaborada por nós no processo superior de desenvolvimento, intelectualizada e socializada com a evolução da fala e o desenvolvimento das funções comunicativas.

1 O sensível infelizmente foi traduzido ao português, por Sentimento e Forma (Feeling and Form), como sentimento, mas o sensível é composto de um processo complexo que envolve a memória, a imaginação, o raciocínio, a emoção, a sensação ou o amalgama de todos ou de cada um deles, o sensível em sua forma mais ampla.

Langer apresenta a arte como manifestação de sensível e aponta, como ideia organizadora da arte, o espectro de emoções, ou os ritmos de sensível, ou ainda a 
sequência do sensível. Conceitos estes retirados de uma análise do professor de teatro Francis Ferguson (1904-1986) em seu A ideia do Teatro. Quando este analisa a obra de Wagner (FERGUSSON, 1953 [1949] : 91/93). Temos então que este espectro de sensível, que estrutura a força organizadora da arte, é onde a vida do sentimento é projetada em uma "projeção atemporal", pois simbólica (LANGER, 1980 : 387), mítica.

Afirma ainda Langer: a arte cria seus elementos, "ao invés de tomá-los do mundo", e assim exibe, ao mesmo tempo tensão e solução, simultaneamente, através da "ilusão de "tensões-espaço" e tensões solução". A arte assim é "aparência de vida, não é vida", e a música é uma "perturbação no ar". A obra de arte mostra-nos, como ainda afirma Langer, uma aparência de vida, tem na formação desta ilusão de vida seu processo mestre, o que dá a qualidade da obra. Assim a Arte não é cópia de sentimento, mas sua presentação simbólica, "conhecimento de sentimento projetado nesta forma articulada atemporal” (LANGER, $1980: 387$, negritos do autor).

Nós apresentamos e encontramos na Arte uma vida do sensível, um fluxo de tensões e soluções, tensões reais, musculares, nervosas, que encontram na arte uma correspondente cadeia simbólica paralela (LANGER, 1980 : 387).

Em seu Filosofia em Nova Chave (1942), obra anterior a Feeling and Form, apresenta Langer os trabalhos artísticos como símbolos icônicos das emoções. De outra forma, em Sentimento e Forma, apresenta a obra de arte não apenas como espelho, mas como transparência, não uma coisa que significa, mas um ícone polisêmico. Um arranjo de elementos do sensível, simbólico e aberto a múltiplas ilações (LANGER, 1980 pg. 60).

As questões levantadas por Langer, ao final da primeira metade do século XX seriam logo adensadas pela arte da performance na segunda metade do mesmo século e seria potencializada no trabalho dos neoconcretos. Estes experimentos diversos, anteriormente apontados neste artigo, não pretendiam apenas superar a biespacialidade do quadro ou que a arte virasse vida no espaço multidimensional, como se afirma em vários de seus manifestos.

47 A arte ganhava com esta experiência, que incorporava o público em seu processo produtivo de sensível, um novo estatuto. A arte, não como uma forma de superação ou integração em amalgama do binômio arte e vida. Arte e vida. Arte é vida, mas Arte é outra forma de vida, onde o público vivencia seu estado e se incorpora num processo continuo de elaboração de estados sensíveis ao produzir novos sensíveis, sentidos e significados.

48 Ainda, como definia Hélio Oiticica, nos velhos anos sessenta, se procurava uma nova fundação ou experiência do objeto na procura de uma arte ambiental. Essa magia do objeto, essa vontade incontida pela construção de novos objetos perceptivos em ato, que se construíam e não eram apenas apresentados previamente, objetos tácteis, visuais, proposicionais, sensíveis, que pudessem aglutinar o que se apresentasse, seja a critica social até a penetração de situações-limite, foram características fundamentais dos trabalhos desta geração. Não apenas introduziam o ser humano na obra, mas o apresentavam como elaborador de sensíveis.

o sempre provocativo Oiticica terminaria em uma auto proclamação: "nossa vanguarda, que é vanguarda mesmo e não arremedo internacional de país subdesenvolvido, como até agora o pensa a maioria de nossas ilustres vacas de presépios da crítica podre e fedorenta" (Oiticica, 1986 : 112).

Seja como for, praticamente cinquenta anos após estas exposições, a obra de arte ainda suscita que seja apresentada a essas novas formas de interação sensível, incorporando o 
ser humano como produtor de significados desta fabrica do sensível, pois de certa forma se abandonou estas utopias dos artistas dos anos 1960/70. Muito de nossas produções recentes ainda se estruturam no terreno confortável da relação emissorreceptor, assim como obras dos artistas aqui envolvidos são muitas vezes mostradas penduradas em museus e galerias, silentes, evitando-se ou censurando-se os questionamentos anteriormente colocados por artistas daquela geração.

\section{BIBLIOGRAFIA}

FAVARETTO, Celso. A Invenção de Hélio Oiticica. EDUSP, São Paulo, 1992.

FERGUSON, Francis. The Idea of a Theater. Anchor Books, Princeton, 1953 [1949]).

JUSTINO, José Maria. Seja Marginal, Seja Herói: modernidade e pós-modernidade em Hélio Oiticica. UFPR, Curitiba, 1998.

LANGER, Susane. Sentimento e Forma. Perspectiva, São Paulo, 1980.

LANGER, Susanne. Filosofia em Nova Chave. Perspectiva, São Paulo, 2004.

LOEB, Angela Varela. Os Bólides do Programa Ambiental de Hélio Oiticica. ARS Ano 9 № 17. pg 49-77. http://www.scielo.br/pdf/ars/v9n17/a04v9n17.pdf.

OITICICA, Hélio. Performer, performance. Nova Iorque, 11/10/1971. PHO 0511/71. http:// www.itaucultural.org.br/aplicexternas/enciclopedia/ho/. Acesso em 10 janeiro de 2018.

OITICICA, Hélio. A dança da minha experiência. 1965. Disponível em http:// www.itaucultural.org.br. Acesso em 10 outubro de 2018.

OITICICA, Hélio. Anotações sobre o "Parangolé" 1964. Disponível em http://www.itaucultural.org.br. Acesso em 10 outubro de 2018.

OITICICA, Hélio. Bases Fundamentais para uma definição de "Parangolé". Disponível em http:// www.itaucultural.org.br. Acesso em 10 outubro de 2018.

OITICICA, Hélio. Parangolé Poético e Parangolé Social. 1966. Disponível em http:// www.itaucultural.org.br. Acesso em 10 outubro de 2018.

OITICICA, Hélio. Posição e Programa. 1966. Disponível em http://www.itaucultural.org.br. Acesso em 10 outubro de 2018.

OITICICA, Hélio Oiticica \& CLARK, Lygia. Cartas: 1964-74. UFRJ, Rio de Janeiro, 1998.

OITICICA, Hélio. Aspiro ao grande labirinto. Rocco, Rio de Janeiro, 1986.

PEDROSA, Mario. Significação de Lygia Clark. In: LYGIA Clark. Rio de Janeiro: Funarte, 1980. p. 14-17

PEDROSA, Mário. Arte ambiental, arte pós-moderna, Hélio Oiticica. Rio de Janeiro: Correio da Manhã, 1966. Transcrito também em Arte em Revista - Pós Moderno. São Paulo: Centro de Estudos de Arte Contemporânea, ano 5, n.7, agosto de 1973.

PEDROSA, Mário. Da natureza afetiva da forma na obra de arte. In M. Pedrosa, Arte, forma e personalidade (pp. 12-82). São Paulo: Kairós, 1979 [1949].

SALOMÃO, Wally. Hélio Oiticica: qual é o parangolé. Relume-Dumará, Rio de Janeiro, 1996. 
Vv. Aa. CATÁLOGO: Hélio Oiticica. Centro de Arte Hélio Oiticica. Galerie nationele du Jeu de Paume, Paris. s.d.

Vv. Aa. Declaração Princípios Básicos da Nova Vanguarda. Catálogo da exposição Nova Objetividade Brasileira ocorrida no MAM-RJ https://vdocuments.site/declaracao-dos-principios-basicos-davanguarda-1967.html 1967

\section{RESUMOS}

A arte de Hélio Oiticica, como de outros participantes da arte de vanguarda brasileira na década de 1970, pretendeu definir novos parâmetros na participação público dentro da obra de arte construindo novas sensibilidades. Esta nova forma de apresentação, relação com o público definiu novos parâmetros o que deu um caráter singular aos trabalhos produzidos pelos participantes deste movimento, que procuravam inserir, de distintas formas o público na sua estrutura e elaboração. Esta nova abordagem explicita novos paradigmas para a arte e define novas formas de conhecimento e participação no objeto artístico. Este trabalho descreve e analisa algumas características particulares deste processo na arte brasileira do período.

L'art d'Hélio Oiticica, tout comme d'autres membres de l'avant-garde brésilienne des années 1970, cherche à définir de nouveaux paramètres de participation du public à l'œuvre d'art en créant de nouvelles sensibilités. Les formes de présentation et de relation avec le public définissent de nouveaux paramètres pour l'œuvre d'art qui lui confèrent un caractère unique. Cette approche définit explicitement des paradigmes nouveaux pour l'art. Elle conçoit aussi des formes inédites de connaissance et de participation propres à l'objet artistique. L'article décrit et analyse certaines caractéristiques de ce processus dans l'art brésilien de l'époque.

\section{ÍNDICE}

Mots-clés: Oiticica (Hélio), Parangolés, neoconcretismo, Langer [Susanne], Clark (Lygia), Pappe (Lygia)

Palavras-chave: Oiticica (Hélio), Parangolés, neoconcretism, Langer [Susanne], Clark (Lygia), Pappe (Lygia)

\section{AUTOR}

\section{ROBSON CORRÊA DE CAMARGO}

Fundador do Programa de Pós Graduação Interdisciplinar em Performances Culturais da UFG (Doutorado e Mestrado). Encenador e crítico de teatro, coordena a Rede Goiana de Pesquisa em Performances Culturais, financiamentos CNPQ, FAPEG, CAPES, FUNAPE. Livros publicados: "Brazilian Theater, 1970-2010" (2015, McFarland, org. with Eva Bueno); "O Gestual no Teatro: Melodrama, Pantomima e Teatro de Feira" (no prelo); "Música na Contemporaneidade" (2015, PUC/GO org. com Claudia Zanini); "O Mundo é um Moinho: Reflexões Sobre o Teatro Popular no séc. XX"; "Performances Culturais" (Hucitec org. com Eduardo Reinato e Heloisa Capel). robson.correa.camargo@gmail.com 